\title{
SHIGELLA TYPE DISTRIBUTION IN JAPAN \\ IN 1951
}

\author{
Rintaro NAKAYA, TETSU NAKAYAMA \\ Erko SAYAMA, AND HIDEO FUKUMI \\ The National Institute of Health \\ (Enterobacteriaceae Center of Japan)
}

Dysentery cases have been increasing in Japan since the end of the second world war. Especially in the year 1951, reported cases were largest during these years. The present paper is dealing with the typing of Shigella strains isolated in Japan during the year 1951, and forwarded to our laboratory mostly for type-identification and partly to meet our request. But the strains examined were not of the exact representation of true type distribution.

\section{RESULTS OF EXAMINATION}

Total number of the strains examined was 866 and the places from Table 1

\begin{tabular}{|c|l|}
\hline \multicolumn{1}{|c|}{ Institutions } & \multicolumn{1}{|c|}{ Locations } \\
\hline $\begin{array}{l}\text { Hospital of Inst. for Infectious Diseases } \\
\text { Tokyo First National Hospital }\end{array}$ & Tokyo \\
Joto Hospital for Infectious Diseases & Tokyo \\
Prefectural Public Health Laboratory & Nagoya, Aichi \\
Utsunomiya, Tochigi & Yamagata, Yamagata \\
Sakata Hospital & Sakata, Yamagata \\
Prefectural Public Health Laboratory & Nagano, Nagano \\
$"$ & Kagoshima, Kagoshima \\
$"$ & Wakayama, Wakayama \\
$"$ & Maebashi, Gumma \\
$"$ & Takamatsu, Kagawa \\
$"$ & Nagoya, Aichi \\
$"$ & Urawa, Saitama \\
$\#$ & Kyoto, Kyoto \\
Okayama, Okayama \\
National Police Reserve Laboratory & Toyama, Toyama \\
First Kosei Hospital & Tokyo \\
Fujin Kyoritsu Orphans' Hospital & Nakakoma, Yamanashi \\
Komagome Hospital for Infectious Diseases & Tokyo \\
Maizuru Kyosai (Mutual Aid) Hospital & Tokyo \\
Tokyo Railroad Hospital & Maizuru, Kyoto \\
& Tokyo \\
\hline
\end{tabular}


which they had been forwarded were as listed in Table 1.

Serological type identification was carried out with the slide agglutination technique, using type and group-antisera. The results of biochemical examination were taken into consideration for further confirmation.

Table 2 Type-distribution of Shigella strains

isolated in 1951

\begin{tabular}{|c|c|c|c|c|c|}
\hline Group & Type & & No. of strains & Subtype & No. of strains \\
\hline $\mathbf{A}$ & $\begin{array}{c}\text { Sh. dysenteriae } \\
" \\
"\end{array}$ & $\begin{array}{r}1 \\
2 \\
3-7\end{array}$ & $\begin{array}{l}4 \\
5 \\
0\end{array}$ & & \\
\hline B & $\begin{array}{l}\text { Sh. flexneri } \\
\text { " } \\
\text { " } \\
\text { " } \\
\text { " var. } \\
\text { " }\end{array}$ & $\begin{array}{l}1 \\
2 \\
3 \\
4 \\
\\
\\
5 \\
6 \\
\mathrm{X} \\
\mathrm{Y}\end{array}$ & $\begin{array}{r}77 \\
502 \\
77 \\
\\
36\end{array}$ & $\begin{array}{l}1 \mathrm{a} \\
1 \mathrm{~b} \\
2 \mathrm{a} \\
2 \mathrm{~b} \\
3 \mathrm{a} \\
3 \mathrm{~b} \\
4 \mathrm{a} \\
4 \mathrm{~b} \\
4 \mathrm{c} \\
4 \mathrm{~d} \\
4 \mathrm{e}\end{array}$ & $\begin{array}{c}4 \\
71 \\
228 \\
264 \\
68 \\
0 \\
3 \\
0 \\
4 \# \\
8 \# \# \\
17\end{array}$ \\
\hline $\mathrm{C}$ & Sh. boydii & $1-7$ & 0 & & \\
\hline D & Sh. sonnei & & 132 & $\left|\begin{array}{cc}\text { Phase } & \text { I } \\
\text { " } & \text { II }\end{array}\right|$ & $\begin{array}{r}127 \\
5\end{array}$ \\
\hline Total & & & 866 & & \\
\hline
\end{tabular}

\# Among them, one strain is of group phase, two strains are mannitol-fermenting and the last one is meannitol-negative.

\#\# Among them three strains are of group phase, two strains are mannitolfermenting.

In this table the numbers of strains in the third and fifth columns do not necessarily agree, because in the early stage of this survey some of the strains were only investigated for their type but not for their subtype. 
The results were as summarized in Table 2. It is clear from the Table that Shigella flexneri 2 is the most prominent type. Type $2 \mathrm{~b}$ is predominating a little more than 2a. The second important types are Shigella sonnei, Shigella flexneri $1 \mathrm{~b}$, Shigella flexneri $3 \mathrm{a}$ in order. Furthermore, all the types, which had been found in Japan, were found this time too. Of Shigella flexneri var. $\mathrm{X}$, which had not been recognized of its existence until 1950, when Sasagawa reported a strain of this variant in Niigata, Japan in $1950^{(1)}$, was found on three occassions this time (1951).

Before, neither of Shigella flexneri $4 \mathrm{a}$ nor $4 \mathrm{~b}$ had been isolated in Japan(2), but this time, 3 strains of $4 \mathrm{a}$ were found. Type $4 \mathrm{~b}$ was not found. Among the strains of Shigella flexneri $4 \mathrm{c}$ and $4 \mathrm{~d}$ examined, two strains in each of them were proved mannitol-positive. Among the strains of Shigella flexneri 3a examined, one strain did not ferment mannitol.

Occurrence of Shigella flexneri var. $\mathrm{X}$ in Japan was already discussed in a previous paper(3). For these years, Shigella flexneri $2 \mathrm{~b}$ had been predominating the type $2 \mathrm{a}$ as seen in Table 2, and this seems to be the reason why Shigella flexneri var. $\mathrm{X}$ has been reported from time to time in Japan during this period, because this type is the second phase (group phase) of Shigella flexneri $2 b$ and splitting off from it.

\section{SUMMARY}

Type-distribution of Shigella isolated in Japan in 1951 is reported herewith.

\section{REFERENCES}

(1) Sasagawa, I.: Presented before the Annual Meeting of Japanese Public Health Association, October 25, 1950.

(2) Fukumi, H., Nakaya, R. and Nakayama, T.: Antigenic structure of Shigella flexneri type 4, Japanese Med. J., 4, 37-72, 1951.

(3) Fukumi, H., Nakaya, R., Nakayama, T. and Sayama, E.: On the distribution of Shigella flexneri type $2 \mathrm{a}$ and $2 \mathrm{~b}$ in Japan, Japanese Med. J., 4, 33-36, 1951. 